\title{
EXTRACTION OF PURE HYDROXYAPATITE FROM PORCINE BONE BY THERMAL PROCESS
}

\author{
Bui Xuan Vuong *, Truong Hoai Linh \\ Faculty of pedagogy in natural sciences, Sai Gon University 273 An Duong \\ Vuong, Dis. 5, HCM City, Vietnam
}

Received 21.03.2019

Accepted 28.03.2019

\begin{abstract}
Natural hydroxyapatite (HA) has been extracted from porcine bone by thermal decomposition without any chemical treatment. The suitable condition to synthesize HA was chosen as a heating bone at $750{ }^{\circ} \mathrm{C}$ during 6 hours. XRD and FTIR analyses confirmed the high purity and crystallinity of synthetic HA. Furthermore, the transformation of the obtained $\mathrm{HA}$ to other phases did not mention up to $1200{ }^{\circ} \mathrm{C}$. TG curve showed a slight loss of mass at $950{ }^{\circ} \mathrm{C}$, but the DSC analysis did not present any physic-chemical phenomena during the period of measurement. FE-SEM images showed the different particles including spheres, scales, and rods in the structure of natural HA. EDX analysis indicated that the $\mathrm{Ca} / \mathrm{P}$ ratio of the synthetic HA is 1.64 , nearly the theoretical value of 1.67. Overall, the results obtained in this study confirmed the success of the thermal process to extract the natural HA from porcine bone.
\end{abstract}

Keywords: hydroxyapatite; porcine bone; thermal process; heating; biomaterials.

\section{Introduction}

Hydroxyapatite (HA) is one of the most attractive biomaterials applied to the bone implant. Its composition and biological structure are similar to natural bone. The main constituent of bone mineral is hydroxyapatite (HA) with a chemical formula of $\mathrm{Ca}_{10}\left(\mathrm{PO}_{4}\right)_{6}(\mathrm{OH})_{2}$ [1-2]. Hydroxyapatite is well known as a biocompatible, osteoconductive, non-toxic, non-inflammatory and non-immunogenic biomaterial. Moreover, it is bioactive and can form a direct chemical bond with living tissues after in vitro or in vivo experiments [3].

Therefore, this biomaterial has been elaborated by many methods. Azade, Y.Y, and Suat, $Y$. have synthesized hydroxyapatite (HA) powders by chemical precipitation through aqueous solutions of the calcium hydroxide $\mathrm{Ca}(\mathrm{OH})_{2}$ and ortho-phosphoric acid $\mathrm{H}_{3} \mathrm{PO}_{4}$ [4]. The study shows that the HA powders with uniform and micro-size spherical

\footnotetext{
*Corresponding author: Bui Xuan Vuong, buixuanvuongsgu@gmail.com
} 
particles can be achieved by a low reaction temperature such as $30{ }^{\circ} \mathrm{C}$ and rapid acid addition rate of $5.5(\mathrm{~mL} / \mathrm{min})$. One dimensional hydroxyapatite (1D HA) has been successfully synthesized by the hydrothermal process [5]. The resulting material expressed in the form of micro-and nanostructures depending on some factors such as types of precursors, $\mathrm{pH}$ and time of reaction mixture. Basam, A.E, et al. have used the sol-gel technique for the preparation of HA nano-powders [6]. The pure HA can be achieved for the samples synthesized at $\mathrm{pH}$ of 7.5 and calcined at $400{ }^{\circ} \mathrm{C}$.

Other researchers have reported the chemical synthesis of HA materials by a microwave-assisted method which permits obtaining the rapid formation of hydroxyapatite nanostructure [7], template-assisted electro-deposition to produce hydroxyapatite nano-wires and nano-tubes [8], and thermal plasma process to synthesize hydroxyapatite nano-sized powders [9].

However, the above synthesis processes might be either complicated or biologically unsafe. So, recently natural hydroxyapatite biomaterial has been extracted by normal calculations of some bio-wastes.

$S$. Ramesh et al. have extracted natural hydroxyapatite from bovine, caprine and galline bones by thermal treatment from $600{ }^{\circ} \mathrm{C}$ to $1000^{\circ} \mathrm{C}$ [10]. The study shows that the natural HA from bovine bone was proved to be stable in the range of temperature evaluated while those separated from caprine and galline showed phase instability with the appearance of tri-calcium phosphate (TCP) after heat treatment beyond $700{ }^{\circ} \mathrm{C}$. Nanorod shape hydroxyapatite with an average length of $300 \mathrm{~nm}$ was obtained by the heat treatment of bovine bone at the temperature of $750^{\circ} \mathrm{C}$ and holding time of $6 \mathrm{~h}$ [11]. A. Pal et al. have synthesized hydroxyapatite from Lates calcarifer fish bone by heat treatment in the temperature ranging from $200{ }^{\circ} \mathrm{C}$ to $1200{ }^{\circ} \mathrm{C}$ [12]. The majority of HA phase was identified in the powders generated after heat treatment over $800{ }^{\circ} \mathrm{C}$. C. F. RamirezGutierrez et al. studied the effect of the temperature and sintering time on the structural property of hydroxyapatite extracted from porcine bone [13]. The experiments were conducted by heating bone powders at $600{ }^{\circ} \mathrm{C}$ and $1000{ }^{\circ} \mathrm{C}$ for $1,7,20$ and 50 hours. The investigations highlighted an increase in crystalline quality as a function of sintering time.

The primary purpose of this study was to extract natural HA from porcine bones by a new thermal process without any chemical treatment. Different steps of direct heating porcine bone were done to decompose the collagen and other organic compounds. The bone samples were evaluated in a wide range of temperatures from $550{ }^{\circ} \mathrm{C}$ to $950{ }^{\circ} \mathrm{C}$ with a fixed treatment time of 6 hours to determine the optimal temperature for HA extraction. After that, the bone samples were heated at different times to determine the suitable conditions of HA extraction. The physic-chemical methods such as XRD, TGDSC, FTIR, and FE-SEM combined with EDX were used to investigate the synthetic materials. 


\section{Materials and methods}

\section{Extraction process}

The porcine bone was boiled for 8 hours to remove the fats and other impurities. After that, the cleaned bone was cut into small round pieces. The thermal decomposition was performed in two steps.

Firstly, the bone was heated at $300{ }^{\circ} \mathrm{C}$ for 2 hours to eliminate organic compounds. The product after this step contained some char due to the burning of organic components. The bone was turned into black color.

Secondly, the black samples were heated at different temperatures and times to remove the remaining char and convert into the ceramic materials. The obtained samples were totally in white and crushed into fine powders.

\section{Physico-chemical characterizations}

The phase and crystallinity of ceramic powders were evaluated by X-ray diffraction (XRD) with a Bruker D8 Advance diffractometer using monochromatic copper radiation $(\mathrm{CuK} \alpha)$ of wavelength $\lambda=0.15406 \mathrm{~nm}$. Powder samples were mixed homogeneously with cyclohexane and dropped on the surfaces of plastic tablets. Then, these tablets were dried to remove the solvent and introduced into diffractometer. The XRD data were acquired with a scanning speed of $1 \% \mathrm{~min}$. The Fourier transformed infrared absorption spectroscopy (FTIR) investigations were carried out with a Bruker Equinox 55 spectrometer to identify the chemical links in the structure of synthetic biomaterials. The FTIR spectrum was recorded over the range from 4000 to $400 \mathrm{~cm}^{-1}$ on pellets obtained by pressing a mixture of $1 \mathrm{mg}$ of ceramic powder and $400 \mathrm{mg}$ of dried $\mathrm{KBr}$ under reduced pressure. The thermal analysis of synthetic materials was evaluated using a Netzsch simultaneous Thermal Analyzer (STA) which incorporates TGA and DSC to measure mass change and heat flow rate simultaneously. Samples $(5 \mathrm{mg})$ were placed on the $\mathrm{Pt} / \mathrm{Rh}$ crucible of the thermobalance and then subjected to the controlled heating rate of $5{ }^{\circ} \mathrm{C} \cdot \mathrm{min}^{-1}$ from ambient temperature to $1200{ }^{\circ} \mathrm{C}$ under the $\mathrm{N}_{2}$ purge flow of $10 \mathrm{~mL} \cdot \mathrm{min}^{-1}$. The analysis data were corrected for baseline drift using instrumental correction runs and the non-parametric baseline fitting function of Peakfit software. An innovative technique, field emission scanning electron microscopy (FE SEM) combined with energy dispersive X-ray spectroscopy (EDX) was carried out to investigate the surface morphology and elemental composition of synthetic materials.

\section{Results and discussion}

\section{$X R D$ investigation}

The XRD diagrams of raw bone and bone heated at different temperatures are represented in Fig. 1. The XRD diagram of raw bone is comprehensive which confirmed the amorphous state of initial material and indicated the presence of low-crystalline crystals of hydroxyapatite. Raw bone consists of 65-70 (wt. \%) inorganic and 30-35 (wt. $\%$ ) organic compounds. Collagen is the leading organic compound present in the natural bone $(95 \%)$, other organic compounds exist in small concentrations such as chondroitin sulfate, keratin sulfate and lipids [10,13]. So, the fibrous collagen and other organic compositions dispersed the X-ray radiations which result in broad peaks in the XRD diagram. 


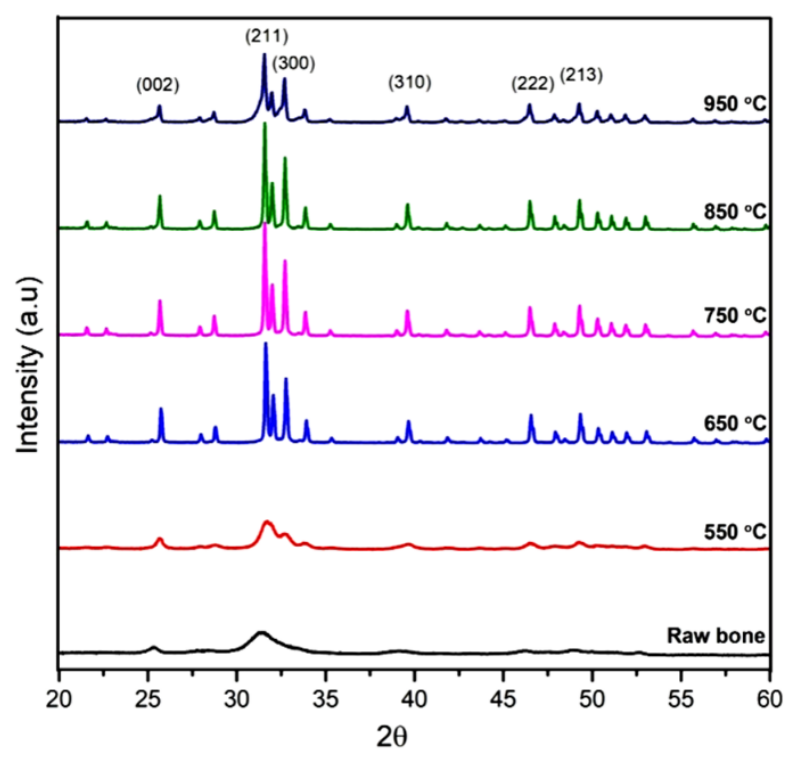

Fig. 1. XRD patterns of raw bone and bone treated at 550; 650; $750 ; 850$ and $950{ }^{\circ} \mathrm{C}$.

The XRD pattern of bone treated at $550{ }^{\circ} \mathrm{C}$ suggested the presence of amorphous calcium phosphate phase (ACP). The diffraction patterns of bone heated from 650 to $950{ }^{\circ} \mathrm{C}$ appeared the narrow and sharp peaks which confirmed the crystalline state of synthetic material. All observed peaks corresponded fully to the ones of the standard XRD diagram of pure hydroxyapatite [14].

Through general observation, it can be found that the XRD diagram of bone treated at 750 and $850{ }^{\circ} \mathrm{C}$ showed the sharpest peaks with the highest intensities by comparing to others. At $950{ }^{\circ} \mathrm{C}$, the characteristic HA peaks were expanded, and their intensities decreased, but the positions of peaks seem to be remaining.

To clarify the above affirmation, the XRD analyses of bone heated have been carefully investigated in several regions selected following the main peaks. Fig. 2 shows a magnification of the XRD diagrams of synthetic materials focused on the peak of nearly $26^{\circ}(002)$. The (002) peak for bone treated at 750 and $850{ }^{\circ} \mathrm{C}$ was similar in both position and intensity while that of the sample at $950^{\circ} \mathrm{C}$ was shifted slightly to the left. 


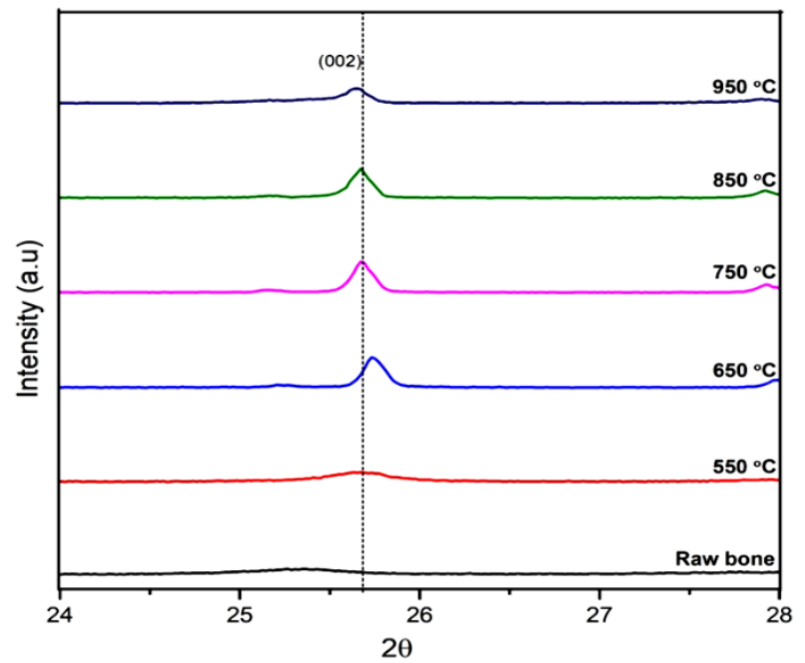

Fig. 2. XRD pattern of raw bone and bone treated in the region of peak $26^{\circ}(2 \theta)$.

For the region from 30 to $35^{\circ}$ (2Ө) including the HA peaks at (211), (112), (300) and (202) as presented in Fig. 3, the same observation was detected. There was almost no change in the shape of the HA characteristic peaks for the bone samples heated at 750 and $850{ }^{\circ} \mathrm{C}$.

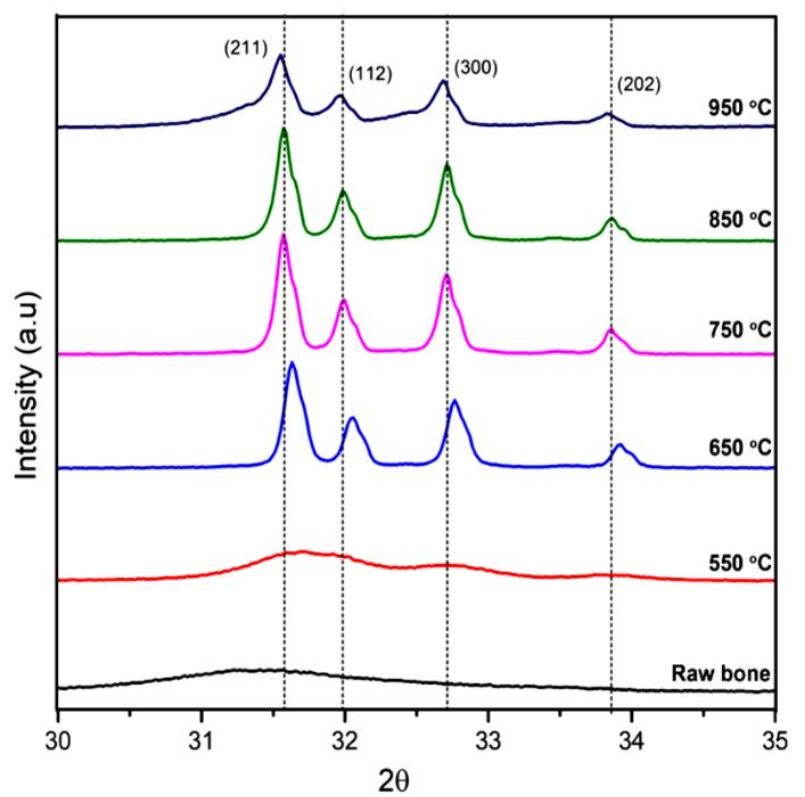

Fig. 3. XRD patterns of raw bone and bone treated in the region from 30 to $35^{\circ}(2 \theta)$. 
The diagram of bone heated at $950{ }^{\circ} \mathrm{C}$ showed a little of change in which the characteristic peaks were moved to the left, widen and their intensities were lower than the ones observed in the XRD of bone treated at 750 and $850{ }^{\circ} \mathrm{C}$. So, the HA can be extracted by heating the bone at the temperatures ranging from 650 to $950{ }^{\circ} \mathrm{C}$ in which the sample treated at 750 and $850^{\circ} \mathrm{C}$ permits synthesizing the natural hydroxyapatite with the best crystalline quality. As more energy efficient, $750{ }^{\circ} \mathrm{C}$ was chosen as temperature for the calcination of the porcine bone.

To investigate the effect of heating times on the formation of hydroxyapatite, the bone samples were treated at $750{ }^{\circ} \mathrm{C}$ for different times from 1 to 10 hours. The XRD diagrams show that the HA phase appeared after only one hour of heating treatment (Fig. $4)$.

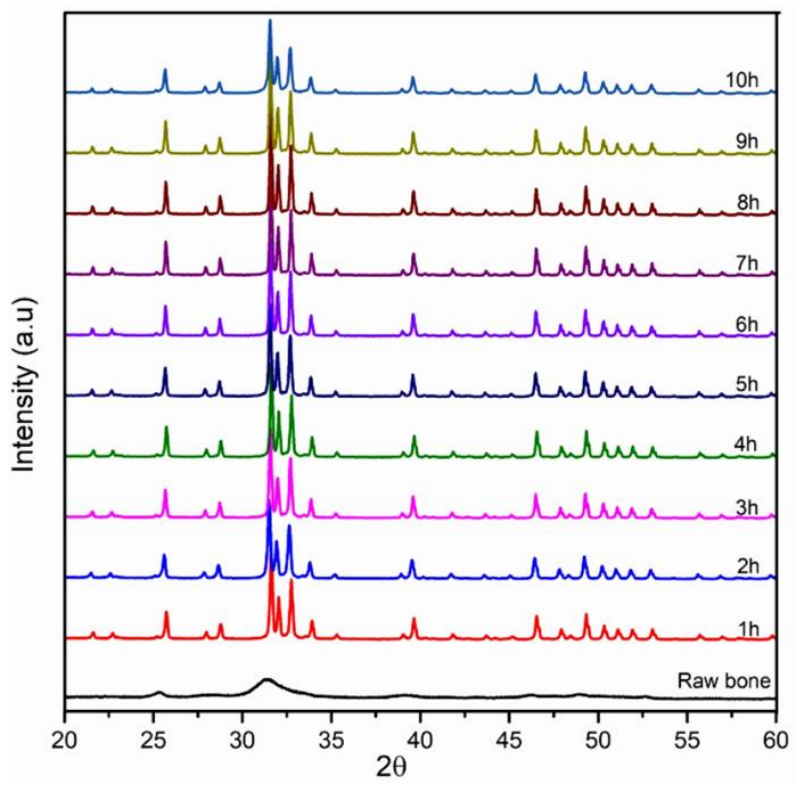

Fig. 4. XRD patterns of raw bone and bone treated at $750{ }^{\circ} \mathrm{C}$ for different times.

For further evaluation, the peak shifts at XRD diagrams were analyzed in two main regions as seen in Fig. 5 and Fig. 6. It is recognized that the bone heated at 1, 2, 3, 4 and 5 hours revealed the peak (002) with a little difference of position while other samples at $6,7,8$ and 9 hours also revealed this peak with the same position and intensity. The bone heated at 10 hours showed the peak (002) shifted to the left (Fig. 5). 


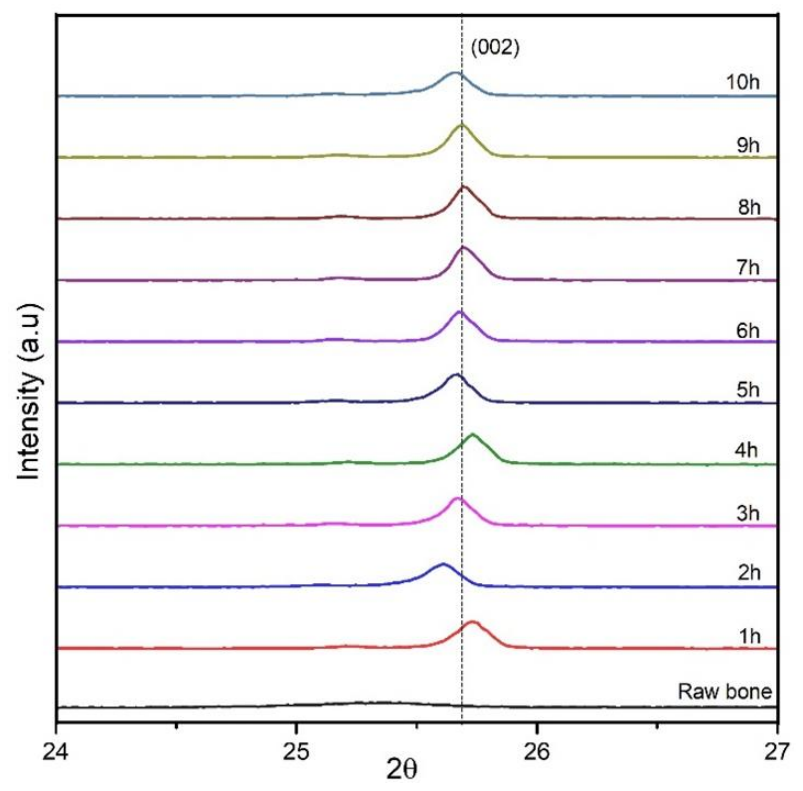

Fig. 5. XRD patterns of bone treated at $750{ }^{\circ} \mathrm{C}$ for different times in the region from 24 to $27^{\circ}(2 \theta)$.

The same observation was mentioned in the XRD diagrams in the region from 30 to $35^{\circ}(2 \theta)$ in which the samples heated from 1 to 5 hours showed the peaks $(211),(112)$, (300) and (202) with their different positions; samples treated from 6 to 9 hours appeared these peaks with their same positions; bone heated for 10 hours had the peaks moved slightly to the left (Fig. 6).

The obtained results can be explained as follows according to the literature [10-11, 13]. When the bone heated at $750{ }^{\circ} \mathrm{C}$ from 1 to 5 hours, there was structural destruction of raw bone following by the recrystallization of $\mathrm{Ca}, \mathrm{P}$ components to form the HA phase. However, the structure of HA is not stable so that the characteristic positions revealed at different positions. The synthetic HA was stable when the bone heated from 6 to 9 hours. Sharp, clear reflections observed correspond to HA which confirmed the phase purity and high crystallinity of HA synthesized by the thermal process at these periods. The slight displacement of the characteristic peaks to the left for the sample heated during 10 hours may be contributed to the signing of phase change at high temperature. Thus, pure and high crystalline HA can be extracted by heating bone at 750 and holding times of $6,7,8$ and 9 hours. With energy efficiency, 6 hours was selected as a time for the calcination of porcine bone.

Briefly summarizing the contents of this section, HA can be extracted by a thermal process. The optimal conditions of HA synthesis can be selected as a heating bone at $750{ }^{\circ} \mathrm{C}$ for 6 hours. This obtained result is according to the research reported in the scientific reference [11], which mentioned that the synthetic hydroxyapatite extracted from bovine bone was obtained by the thermal process at the temperature of $750{ }^{\circ} \mathrm{C}$ and holding time of 6 hours. The natural HA obtained by heating bone at $750{ }^{\circ} \mathrm{C}$ for 6 hours will be served for further characterizations. 


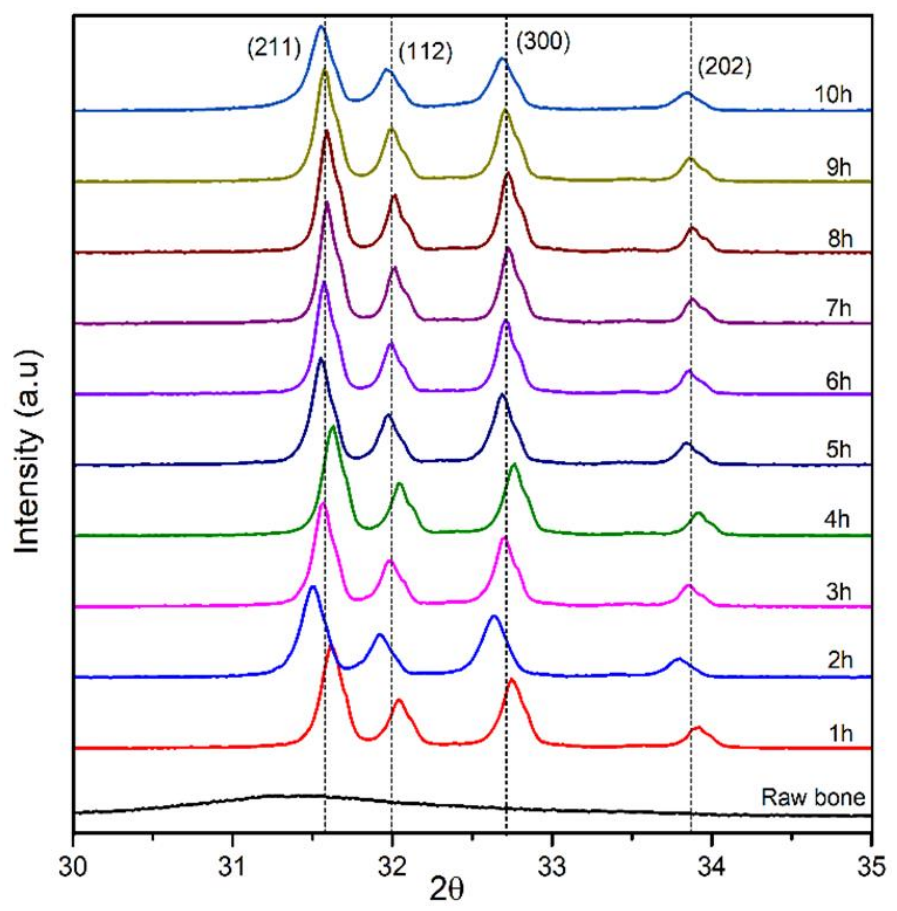

Fig. 6. XRD patterns of bone treated at $750{ }^{\circ} \mathrm{C}$ for different times in the region from 30 to $35^{\circ}(2 \theta)$.

\section{TG-DSC information}

The results of thermogravimetric analysis (TGA) and differential scanning calorimetry (DSC) of natural hydroxyapatite extracted from porcine bone by heating at $750{ }^{\circ} \mathrm{C}$ for 6 hours are shown in Fig. 7 .

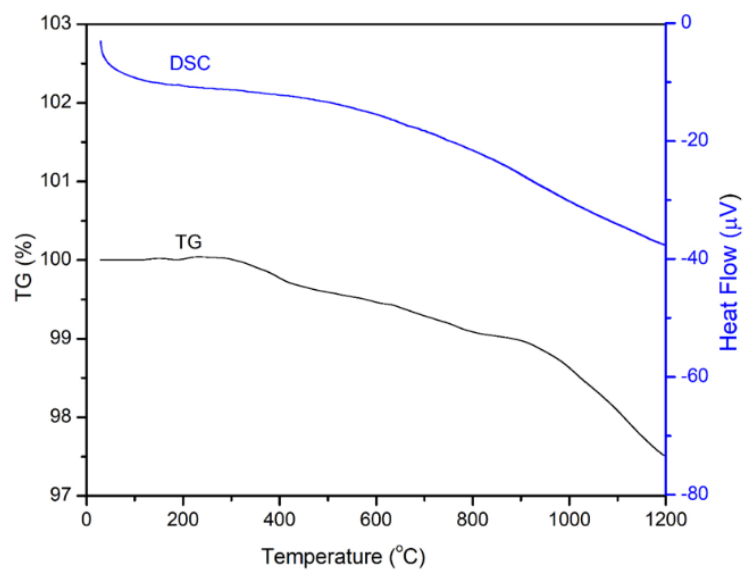

Fig. 7. The TG-DSC curves of natural HA obtained by heating bone at $750{ }^{\circ} \mathrm{C}$ during 6 hours. 
A small weight loss was detected by TGA calculation while the DSC curve did not mention any phenomena. Thus, the analysis of TGA-DSC indicated that the synthetic HA produced by treating bone at $750{ }^{\circ} \mathrm{C}$ during 6 hours is stable up to $1200{ }^{\circ} \mathrm{C}$.

It is recognized that there was a slight loss of mass observed in the TG curve at about $950{ }^{\circ} \mathrm{C}$ although the DSC did not show any apparent phenomena. This mass loss corresponds to the slight change of structure by observing the displacement of characteristic peaks in the XRD diagram when bone heated at $950{ }^{\circ} \mathrm{C}$. However, this change is not effective enough to create the physicochemical phenomena as observed by the DSC curve.

This obtained analysis is consistent with the previous study [15] which reported that the natural hydroxyapatite extracted from bovine bone is stable up to $1100{ }^{\circ} \mathrm{C}$. The analysis by TGA-DSC reconfirmed the optimal conditions to synthesize the natural hydroxyapatite from porcine bone to prevent phase transformation.

\section{FTIR analysis}

The FTIR spectrum of the synthetic HA (Fig. 8) is in good agreement with the reference [17]. In this figure, the stretching band at $3571 \mathrm{~cm}^{-1}$ and vibration band at $630 \mathrm{~cm}^{-1}$ originate from $\mathrm{OH}^{-}$groups. The bands located at 564, 600, 962, 1026, and $1088 \mathrm{~cm}^{-1}$ originate by $\mathrm{PO}_{4}{ }^{3-}$ ions [1-4]. The bands at $812,887,1422$, and $1483 \mathrm{~cm}^{-1}$ originate from $\mathrm{CO}_{3}{ }^{2-}$ ions. Carbonate ions are a common impurity in FTIR measurement. The results of FTIR analyses in the present investigation showed that the HA obtained by the conversion of bone at $750{ }^{\circ} \mathrm{C}$ in 6 hours is pure.

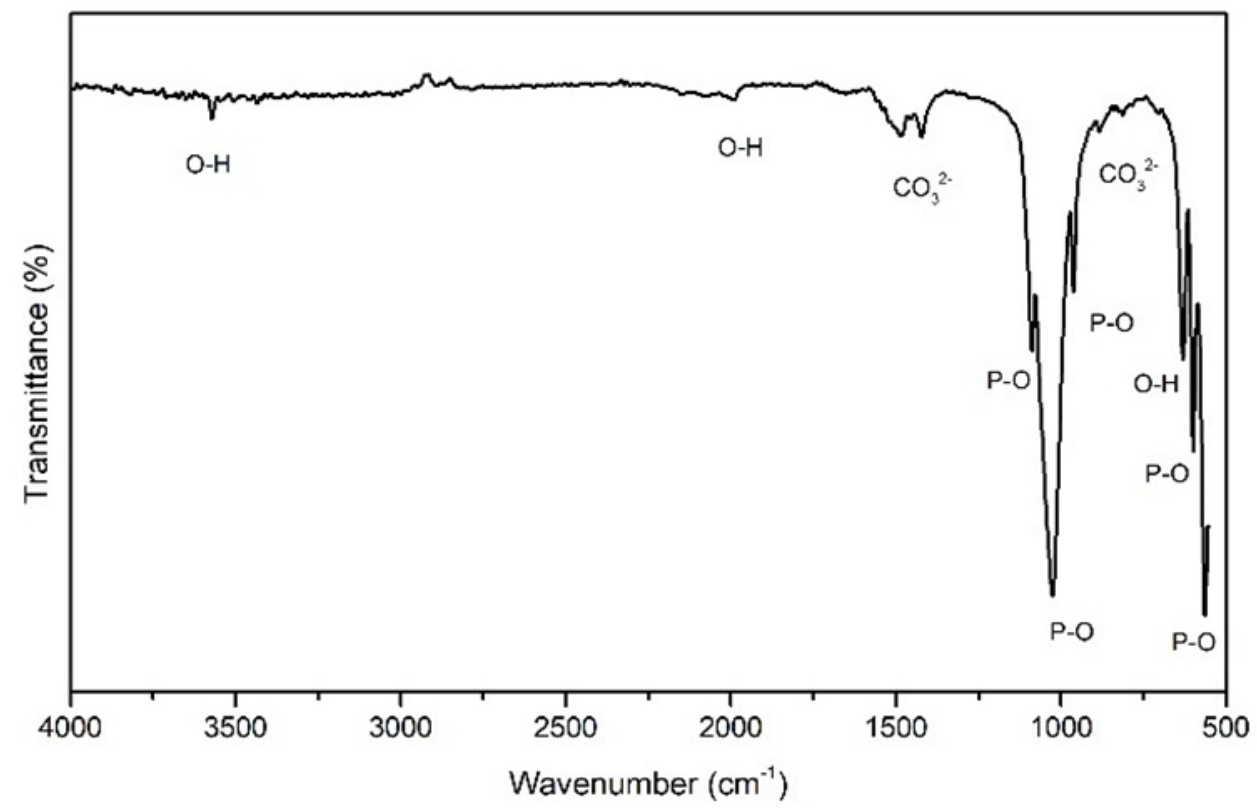

Fig. 8. The FTIR spectrum of natural HA obtained by heating bone at $750{ }^{\circ} \mathrm{C}$ during 6 hours. 


\section{FE-SEM and EDX characterizations}

The surface morphology of the obtained hydroxyapatite extracted from porcine bone has been observed by FE-SEM technique. Fig. 9 presents the FE-SEM micrographs of synthetic HA at different magnifications. At 5000 and 10.000 magnifications, the surface of material shows the particles agglomerated in some parts and have irregular shapes including small spheres, scales, and rods. These different particles are interconnected to create the porous 3D structure of the material. The FE-SEM images at higher magnifications of 20.000 and 50.000 clearly show the rods, scales, and pores in the structure of synthetic HA. The result obtained by FE-SEM is quite similar to the one reported in the reference, in which the authors have extracted the HA material from bovine bone [13].
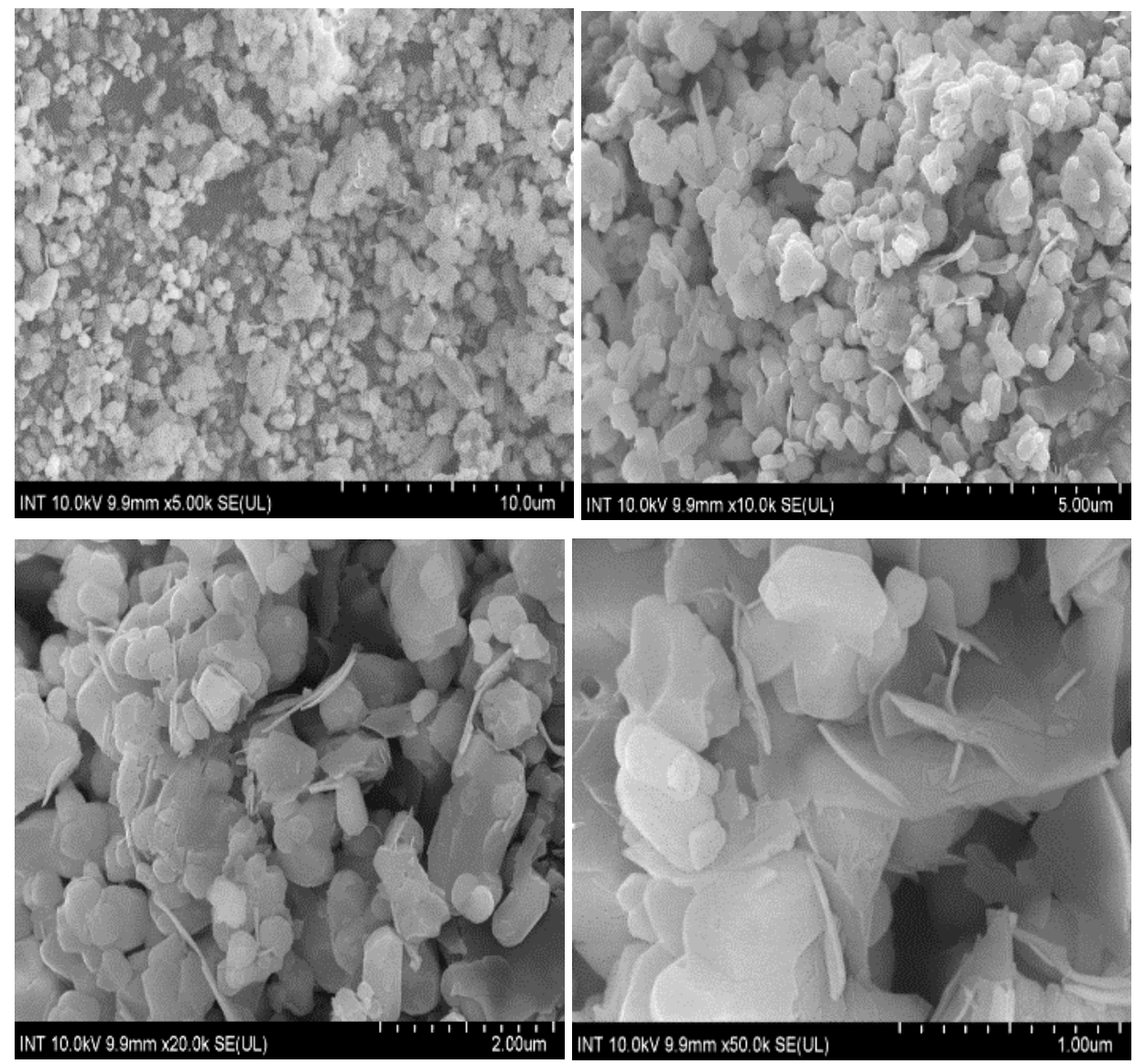

Fig. 9. FE-SEM images of natural HA obtained by heating bone at $750{ }^{\circ} \mathrm{C}$ for 6 hours. 
The EDX analysis is given in Fig. 10; this is considered as a reference to compare the $\mathrm{Ca} / \mathrm{P}$ molar ratio of synthetic material with the one in the theory of $\mathrm{HA}$ formula. The $\mathrm{Ca} / \mathrm{P}$ ratio for the extracted HA is 1.64 which is very near the theoretical value of 1.67. The $\mathrm{Ca} / \mathrm{P}$ ratio for natural HA of this study is similar to those of HA obtained by thermal decomposition, subcritical water, and alkaline hydrothermal processes $[11,13,15]$.

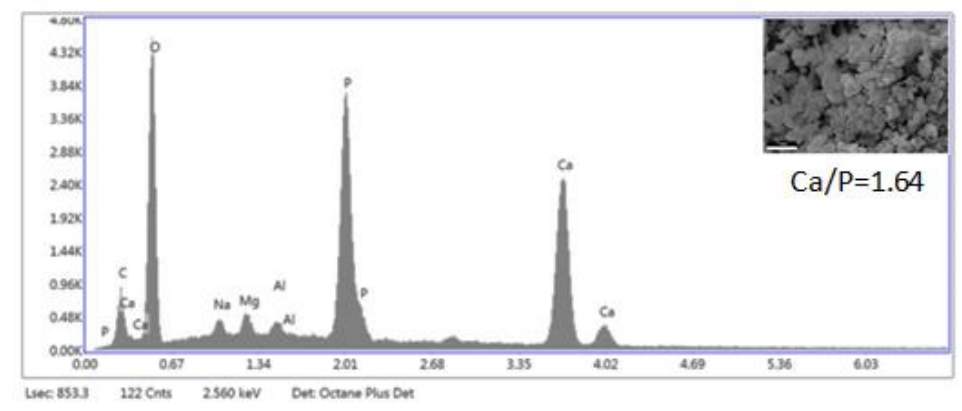

Fig. 10. EDX elemental analysis of natural HA obtained by heating bone at $750{ }^{\circ} \mathrm{C}$ during 6 hours.

\section{Conclusion}

This study showed that porcine bone could be exploited as a natural source for the elaboration of hydroxyapatite. The thermal process is starting by burning bone to remove organic compounds and then heating to produce hydroxyapatite material. The results analyzed by XRD showed that the suitable condition of HA synthesis is the thermal treatment of bone at $750{ }^{\circ} \mathrm{C}$ for 6 hours. The obtained material is pure and highly crystalline. Also, TG-DSC analysis confirmed the stability of synthetic HA from ambient temperature up to $1200{ }^{\circ} \mathrm{C}$. FE-SEM observation showed the structural morphology of synthetic HA which including small spheres, scales and rods with different sizes and shapes. EDX analysis confirmed that the molar ratio of $\mathrm{Ca} / \mathrm{P}$ of synthetic $\mathrm{HA}$ is 1.64 which is very closely to the theoretical value. The advantage of the thermal process in this study is low cost, simple synthesis process and possible to produce a large quantity of natural HA.

\section{References}

[1] J. Kolmas, S. Krukowski, A. Laskus, M. Jurkitewicz: Ceram Inter, 42 (2016) $2472-$ 2487.

[2] A. Rogina, M. Ivanković, H. Ivanković: Mater Sci Eng C, 33 (2013) 4539-4544.

[3] W. Xiao, B. B. Sonny, M. N. Rahaman: Mater Sci Eng C, 60 (2016) 324-332.

[4] Y. Suat: Ceram Inter, 44 (2018) 9703-9710.

[5] Z. S. Stojanović, N. Ignjatović, V. Wu, V. Žunič, Lj. Veselinović, S. Škapin, M. Miljković, V. Uskoković, D. Uskoković: Mater Sci Eng C, 68 (2016) 746-757.

[6] B. A. Ben-Arfa, I. M. Miranda Salvado, J. MF Ferreira, R. C. Pullar: Mater Sci Eng C, 70 (2017) 796-804.

[7] M. N. Hassan, M. M. Mahmoud, A. A. El-Fattah, S. Kandil: Ceram Inter, 142 (2016) 3725-3744. 
[8] S. Beaufils, T. Rouillon, P. Millet, J. Le Bideau, P. Weiss, J. P. Chopart, A. L. Daltin: Mater Sci Eng C, 98 (2019) 333-346.

[9] J. H. Seo, B. G. Hong: Nuc Eng Tech, 44 (2012) 9-20.

[10] S. Ramesh, Z. Z. Loo, C. Y. Tan, WJ Kelvin Chew, Y. C. Ching, F. Tarlochan, Hari Chandran, S. Krishnasamy, L. T. Bang, A. A. Sarhan: Ceram Inter, 44 (2018) 10525-10530.

[11] N. A. Barakat, M. S. Khil, A. M. Omran, F. A. Sheikh, H. Y. Kim: J Mater Process Tech, 209 (2009) 3408-3415.

[12] A. Pal, S. Paul, A. R. Choudhury, V. K. Balla, M. Das, A. Sinha: Mater Lett, 203 (2017) 89-92.

[13] C. F. Ramirez-Gutierrez, S. M. Londoño-Restrepo, A. del Real, M. A. Mondragón, M. E. Rodriguez-García: Ceram Inter, 43 (2017) 7552-7559.

[14] Hydroxyapatite Standard ICDD 9-432.

[15] M. E. Bahrololoom, M. Javidi, S. Javadpour, J. Ma: J Ceram Process Res, 10 (2009) 129-138.

(c) (†) Creative Commons License

This work is licensed under a Creative Commons Attribution 4.0 International License. 